\title{
ON THE STABILITY OF FUNCTIONAL EQUATIONS WITH SQUARE-SYMMETRIC OPERATION
}

\author{
GWANG HUI KIM
}

\begin{abstract}
In this paper, we obtain the modified Hyers-Ulam-Rassias stability for the family of functional equations $f(x \circ y)=H(f(x), f(y))(x, y \in S)$, where $H$ is a homogeneous function and $\circ$ is a square-symmetric operation on the set $S$. As a consequence we obtain the Hyers-Ulam stability of its functional equation.
\end{abstract}

Mathematics subject classification (2000): 39B52, 39B72, 39B82.

Key words and phrases: Functional equation, Homogeneous function, Hyers-Ulam stability, (modified) Hyers-Ulam-Rassias stability.

\section{REFERENCES}

[1] Borelli-ForTI, C. \& ForTI, G.-L., On a general Hyers-Ulam stability result, Internat. J. Math. Math. Sci. 18 (1995), 229-236.

[2] P. GǍVRUTA, A Generalization of the Hyers-Ulam-Rassias stability of approximately additive mappings, J. Math. Anal. Appl. 184 (1994), 431-436.

[3] D. H. HYERS, On the stability of the linear functional equation, Proc. Nat. Acad. Sci. U. S. A. 27 (1941), 222-224.

[4] D. H. Hyers, G. IsAC AND Th. M. RASSIAS, Stability of the Functional Equations in Several Variables, Birkhäuser Verlag, 1998.

[5] D. H. Hyers AND TH. M. RASSIAS, Approximate homomorphisms, Aeqnat. Math. 44 (1992), 125-153.

[6] Zsolt PÁLES, Generalized stability of the Cauchy functional equation, Aequationes Math. 56 (1998), 222-232.

[7] Zsolt PÁles, Peter Volkmann and Duncan Luce, Stability of Functional Equations with Square-Symmetric Operations, Proc. Natl. Acad. Sci. 95,Issue 22 (1998), 12772-12775.

[8] TH. M. RASSIAS, On the stability of the linear mapping in Banach spaces, Proc. Amer. Math. Soc. 72 (1978), 297-300.

[9] _ On the modified Hyers-Ulam sequence, J. Math. Anal. Appl. 158 (1991), 106-113.

[10] TH. M. RASSIAS AND P. ŠEMRL, On the behavior of mappings which do not satisfy Hyers-Ulam stability, Proc. Amer. Math. Soc. 114 (1992), 989-993.

[11] TH. M. RASSIAS AND J. TABOR, What is left of Hyers-Ulam stability, J. Nat. Geometry 1 (1992), 65-69.

[12] S. M. Ulam, "Problems in Modern Mathematics" Chap. VI, Science editions, Wiley, New York, 1964. 